\title{
Assessing confidence intervals for stratigraphic ranges of higher taxa: The case of Lissamphibia
}

\author{
David Marjanović and Michel Laurin \\ Acta Palaeontologica Polonica 53 (3), 2008: 413-432 doi:http://dx.doi.org/10.4202/app.2008.0305
}

To evaluate stratigraphic evidence for the time of origin of the clade of extant amphibians (Lissamphibia), we attempt to establish a confidence interval on the lower bound of the stratigraphic range of this clade. This is based on the stratigraphic distribution of 1207 fossiliferous localities that have yielded lissamphibians, the relative area of sedimentary rocks from various periods (upper Paleozoic to present) exposed on the continents, and ten exponential-growth models of lissamphibian diversity that differ by the assumed effects of three major biological crises and the assumed starting times of lissamphibian diversification. The results suggest a more recent origin of Lissamphibia than advocated in most recent molecular studies. They are also more compatible with monophyly than with polyphyly of the extant amphibians, but heavily depend on poorly constrained assumptions about lissamphibian extinction rates during biological crises. Counts of lissamphibian diversity through time that consider ghost lineages and stage durations show moderate declines across the Cretaceous-Paleogene and Oligocene-Miocene boundaries.

Key words: Lissamphibia, origination time, evolution of biodiversity, stratigraphic range, fossil record, mass extinction

David Marjanović [david.marjanovic@gmx.at] and Michel Laurin [michel.laurin@upmc.fr], UMR CNRS 7179, Université Paris 6, 4 place Jussieu, case 19, 75005 Paris, France.

This is an open-access article distributed under the terms of the Creative Commons Attribution License (for details please see creativecommons.org), which permits unrestricted use, distribution, and reproduction in any medium, provided the original author and source are credited. 
FoF Supplementary file $(40.3 \mathrm{kB})$ 